\title{
Analysis of KRT5 and KRT14 gene mutations and mode of inheritance in Iranian patients with clinical suspicion of Epidermolysis bullosa simplex
}

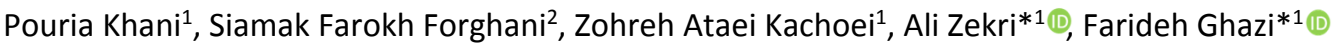

Received: 14 Apr 2019

Published: 4 May 2020

\section{Abstract}

Background: Epidermolysis bullosa simplex is a hereditary skin disorder caused by mutations in several genes such as KRT5 and KRT14. Skin fragility in basal keratinocytes presence regions led to the cytolysis of epidermis and blistering. Aim of this study was to detect the molecular defects in KRT5 and KRT14 genes hot spots in patients with clinical suspicion of EBS and investigation of their probable genotype-phenotype correlations.

Methods: Exons 1 and 6-7 of KRT5 and exons 1 and 4-7 of KRT14 amplification and mutation detection were performed by polymerase chain reaction and Sanger sequencing, respectively. Novel variants pathogenicity evaluated by bioinformatics tools.

Results: Nine important variants detected in seven different patients within 6 Iranian families affected by Epidermolysis bullosa simplex, of which four variants were novel. Three patients had a mottled pigmentation phenotype [G96D (p.Gly96Asp) and F97I (p.Phe97Ile) in KRT5]. One of them showed a Dowling-Meara phenotype [A417P (p.Ala417Pro) and E477D (p.Glu477Asp) in KRT5] and another had a Koebner type phenotype [R397I (p.Arg397Ile) and Q444* (p.Gln444Ter) in KRT5]. A novel variant [G92E (p.Gly92Glu) in KRT5] in a double heterozygous state with a challenging variant [A413T (p.Ala413Thr) in KRT14] identified in one patient with Koebner type phenotype. Also, a previously reported mutation [I377T (p.Ile377Thr) in KRT14 gene] identified in this study.

Conclusion: The results of molecular data analysis showed that the most severe phenotypes were associated with mutations in highly conserved regions. In some cases, different inheritance modes were observed.

Keywords: Epidermolysis bullosa simplex, Skin fragility, Keratin

Conflicts of Interest: None declared

Funding: This study was supported by a research committee foundation grant no. 96-01-30-30550 of Iran University of Medical Sciences

*This work has been published under CC BY-NC-SA 1.0 license.

Copyright $\odot$ Iran University of Medical Sciences

Cite this article as: Khani P, Farokh Forghani S, Ataei Kachoei Z, Zekri A, Ghazi F. Analysis of KRT5 and KRT14 gene mutations and mode of inheritance in Iranian patients with clinical suspicion of Epidermolysis bullosa simplex. Med J Islam Repub Iran. Med J Islam Repub Iran. 2020 (4 May);34:43. https://doi.org/10.47176/mjiri.34.43

\section{Introduction}

Epidermolysis bullosa simplex (EBS) is a group of genodermatoses characterized by fragility of the skin and

separation of tissue through basal keratinocytes that resulted in intraepidermal blistering upon mild mechanical
Corresponding author: Dr Ali Zekri, zekri.a@iums.ac.ir Dr Farideh ghazi, ghazi.f@iums.ac.ir

1. Department of Medical Genetics and Molecular Biology, Faculty of Medicine, Iran University of Medical Sciences, Tehran, Iran

2. Burn Research Center, Iran University of Medical Sciences, Tehran, Iran $\uparrow$ What is "already known" in this topic:

Epidermolysis bullosa simplex (EBS) is one of the most common genetic bullous skin diseases characterized by the separation of the skin at the basal keratinocytes region after trauma and blister formation. The most important and most commonly occurring molecular defects in these patients are the defects of keratins 5 and14 (KRT5 and KRT14).

$\rightarrow$ What this article adds:

Exons 1 and 6-7 of KRT5 and exons 1 and 4-7 of KRT14 mutation detection were performed in this study. The results of molecular analyzing showed that the most severe phenotypes were associated with mutations in highly conserved regions. In some cases, different inheritance modes were observed. These mutations showed regional variations useful in genetic counseling and prenatal testing in different ethnic groups. Our data demonstrated the heterogenic status of KRT5 and KRT14 genes mutations. 
trauma (1). Among all EB cases, the most common subtype is EBS, with an approximate prevalence of 1 in 25 000-50 $000(2,3)$. However, the prevalence of EBS in Iran remains unknown. Localized EBS (the mildest form), generalized intermediate EBS, EBS-with mottled pigmentation and generalized severe EBS (Dowling-Meara type) are the most common subtypes of EBS $(4,5)$.

The underlying mutations in EBS are mostly affected by KRT5 and KRT14. These genes encode keratin 5 (K5) and 14 (K14) that typically expressed in the epidermal basal layer $(6,7)$. Keratin filaments are part of cytoskeletal intermediate filament proteins. Interactions between keratin 5 and 14 filaments using their $\alpha$-helical rod domains to bundle formation have essential roles for strength and flexibility to basal keratinocytes and maintenance of epidermis integrity and resilience against physical traumas (7-10). Recessive mutations are usually reported in KRT14 gene, while dominant mutations (especially missense mutations) have been seen in both genes (11-13). In the Western world (with a low prevalence of consanguineous marriage) remarkable proportion of EBS cases have autosomal dominant inheritance pattern, whereas in regions or countries with a high prevalence of inbreeding, autosomal recessive inheritance is more prevalent $(11,14)$. Through analysis of phenotype-genotype correlation has been revealed that mutation in highly conserved regions in keratin molecule (two terminals of the central rod section) is usually related to a severe phenotype (generalized severe EBS). Mutations in less conserved areas are related to milder phenotypes (e.g., Localized EBS) (15-17). Moreover, the nature of the amino acid alteration affects the severity of the disease $(18,19)$.

In this study, we carried out the analysis of molecular genetics of keratin mutations in 12 families of Iranian patients suspected to Epidermolysis bullosa simplex to investigate the mode of inheritance and correlation between genotype-phenotype. At the end of this study, we debate how these molecular alterations create different phenotypic manifestations.

\section{Methods}

Patient selection: According to precise clinical examinations, family history and pattern of inheritance, 15 patients in 12 families diagnosed with EBS. Criteria of diagnosis for patient selection and their classification were based on the report of the Third international consensus meeting on diagnosis and classification of Epidermolysis bullosa (20). After approval by the Medical Ethics Committee of Iran University of Medical Sciences, all patients and their families contributed to this study with fully informed consent for sample collection and sequencing of DNA. Then $5 \mathrm{ml}$ of blood was collected into Ethylenediaminetetraacetic acid tubes from patients and their relatives.
PCR and Mutation detection: Genomic DNA was isolated from peripheral blood leukocytes using the saltingout method (21). Polymerase chain reaction (PCR) amplification of KRT5 exons 1, 6-7, KRT14 exons 1, 4-7 and their flanking intronic sequences performed. The sequence of primers used for PCR amplification of the specific amplicons was described previously (Table 1) (22). Each PCR reaction was contained $12.5 \mu \mathrm{l}$ of PCR master mix, $2.5 \mu$ l of genomic DNA (Approximately 100-150 ng of DNA), $0.4 \mu 1$ of forward primer (with a concentration of $10 \mathrm{pmol} / \mathrm{ul}$ ), $0.4 \mu \mathrm{l}$ of reverse primer (with a concentration of $10 \mathrm{pmol} / \mathrm{ul}$ ) and $9.2 \mu \mathrm{l}$ of double-distilled water. Initial denaturation at $94{ }^{\circ} \mathrm{C}$ for $5 \mathrm{~min}$ and then 30 amplification cycles were performed with a program contained 1 min at $94{ }^{\circ} \mathrm{C}, 1 \mathrm{~min}$ at $60{ }^{\circ} \mathrm{C}$ and $1 \mathrm{~min}$ at $72{ }^{\circ} \mathrm{C}$ with a final incubation of $5 \mathrm{~min}$ at $72{ }^{\circ} \mathrm{C}$ for all of the exons were the same except primers of KRT14 exon 4-7 that their annealing temperature was $63{ }^{0} \mathrm{C}$ (to avoid amplification of the KRT14 pseudogene). PCR Products purified and sequenced (using ABI 3730XL DNA Sequencer by Macrogen Company). For the detection of mutations, PCR product sequences were compared with sequences obtained from GenBank accession number NM_000424.3 as a reference sequence for KRT5 and GenBank accession number NM_000526.3 as a reference sequence for KRT14 (http://www.ncbi.nlm.nih.gov/).

\section{Results}

Phenotypic observations: From the 12 families, 15 affected individuals were clinically evaluated (Table 2). An explicit EBS-DM (Dowling-Meara) phenotype in four probands from 4 unrelated families and an ambiguous phenotype in an intermediate mode between DowlingMeara and Koebner type in one patient (patient 5) were observed. Three patients from 2 unrelated families showed EBS with mottled pigmentation phenotype. Five patients from 3 different families had a Koebner type of EBS. Also, 2 patients in 2 separate families showed a Weber-Cockayne phenotype. The eldest and youngest patients were 48 and 4 years old, respectively. The prevalence of consanguineous marriages among the selected families was $58.3 \%$ and families were from several different Iranian ethnic groups. Clinical features of patients have been shown in Figure 1.

Keratin mutation identification: Sequence analysis of the KRT5 and KRT14 genes revealed 9 variants that are listed in Table 3 and Figure 2. Four variants have not been reported previously and five are known. 8 of 9 variants were missense and one was nonsense. Four novel variants with probable pathologic importance in KRT5 were c.289T $>A$ in exon 1 (patients 1,2 and 15), c.1190G $>\mathrm{T}$ in exon 6 and c.1330C $>\mathrm{T}$ in exon 7 (patient 14), c.1249G $>\mathrm{C}$ in exon 7 (patient 5). Despite the previous report from two

Table1. Primers and their sequences

\begin{tabular}{lcc}
\hline & & Primer (Sequence 5' to 3') \\
\cline { 2 - 3 } Gene / exon & Forward & Reverse \\
KRT5/e1 & AGCTCTGTTCTCTCCAGCAC & CAGTCTAATTCAGAACGTGTCC \\
KRT5/e6-7 & TCACTGCCTGTGAACTTTGG & GGCCATGAGTCAGACTGAAA \\
KRT14/e1 & TTACCCGAGCACCTTCTCTTC & TGCTGGAGAACAAGTAGCTGC \\
KRT14/e4-7 & GGCCTAAGGAACACCAATCC & CACTAGAGCTCAGCCCCTCA \\
\hline
\end{tabular}




\begin{tabular}{|c|c|c|c|c|c|}
\hline Family & Patient & Sex & Age & Phenotype & Clinical features \\
\hline \multirow[t]{4}{*}{1} & 1 & Female & 52 & mottled pigmentation & Spontaneous blistering after a minor trauma \\
\hline & 2 & Male & 27 & & Nail dystrophy (Fig. 2a) \\
\hline & & & & & Reticulate skin pigmentation \\
\hline & & & & & Keratoderma \\
\hline \multirow[t]{5}{*}{2} & 3 & Male & 7 & Dowling-Meara & Onset age: at birth \\
\hline & & & & & $\begin{array}{l}\text { Blisters in herpetiform clusters on the trunk and proximal ex- } \\
\text { tremities }\end{array}$ \\
\hline & & & & & Nail dystrophy and then nail losing \\
\hline & & & & & Mucosal involvement: esophagus \\
\hline & & & & & Teeth involvement \\
\hline \multirow[t]{6}{*}{3} & 4 & Male & 10 & Koebner type & Onset age: early infancy \\
\hline & & & & & Blistering after minor trauma (Fig. 2c) \\
\hline & & & & & Mucosal involvement \\
\hline & & & & & Teeth involvement \\
\hline & & & & & Nail losing \\
\hline & & & & & Hyperkeratosis of the palms and soles \\
\hline \multirow[t]{5}{*}{4} & 5 & Male & 48 & Dowling-Meara & Onset age: at birth \\
\hline & & & & & Nail dystrophy (Fig. 2b) and then nail losing \\
\hline & & & & & Mucosal involvement: esophagus \\
\hline & & & & & Teeth involvement \\
\hline & & & & & Hypopigmentation and hyperpigmentation (Fig. 2b) \\
\hline \multirow[t]{3}{*}{5} & 6 & Male & 36 & Weber-Cockayne & Onset age: adolescence \\
\hline & & & & & Blistering: typically restricted to hands and feet \\
\hline & & & & & Healing of blisters with minor scarring \\
\hline \multirow[t]{5}{*}{6} & 7 & Male & 6 & Weber-Cockayne & Onset age: early infancy \\
\hline & & & & And & Blistering in whole body surface that typically restricted to \\
\hline & & & & Koebner type & hands and feet (after a minor trauma) \\
\hline & & & & & Mucosal involvement \\
\hline & & & & & Nail losing (2 fingers) \\
\hline \multirow[t]{5}{*}{7} & 8 & Female & 8 & Dowling-Meara & Onset age: at birth \\
\hline & & & & & $\begin{array}{l}\text { Blisters in herpetiform clusters on the trunk and proximal ex- } \\
\text { tremities }\end{array}$ \\
\hline & & & & & Nail dystrophy and then nail losing \\
\hline & & & & & Mucosal involvement: esophagus \\
\hline & & & & & Progressive hyperkeratosis of the palms \\
\hline \multirow[t]{5}{*}{8} & 9 & Female & 8 & Dowling-Meara & Onset age: at birth \\
\hline & & & & & $\begin{array}{l}\text { Blisters in herpetiform clusters on the trunk and proximal ex- } \\
\text { tremities }\end{array}$ \\
\hline & & & & & Nail losing \\
\hline & & & & & Mucosal involvement: esophagus \\
\hline & & & & & Milia \\
\hline \multirow[t]{7}{*}{9} & 10 & Female & 12 & Dowling-Meara & Onset age: at birth \\
\hline & & & & & Generalized blistering \\
\hline & & & & & Mucosal involvement: esophagus \\
\hline & & & & & Progressive hyperkeratosis of the palms \\
\hline & & & & & Nail losing \\
\hline & & & & & Milia \\
\hline & & & & & Progressive hyperkeratosis of the soles \\
\hline \multirow[t]{5}{*}{10} & 11 & Male & 24 & Koebner type & Onset age: early infancy \\
\hline & 12 & Male & 31 & & Nail dystrophy and then nail losing \\
\hline & 13 & Male & 22 & & Mucosal involvement: esophagus \\
\hline & & & & & Hypopigmentation and hyperpigmentation \\
\hline & & & & & Hyperkeratosis of the palms and soles \\
\hline \multirow[t]{6}{*}{11} & 14 & Female & 41 & Koebner type & Onset age: early infancy \\
\hline & & & & & Generalized blistering after a minor trauma \\
\hline & & & & & Nail losing \\
\hline & & & & & Teeth involvement \\
\hline & & & & & Mucosal involvement \\
\hline & & & & & Hypopigmentation and hyperpigmentation \\
\hline \multirow[t]{3}{*}{12} & 15 & Female & 38 & mottled pigmentation & Onset age: at birth \\
\hline & & & & & Occasionally Skin blistering: restricted to hands and feet \\
\hline & & & & & Reticulate skin pigmentation \\
\hline
\end{tabular}

variants [c.287G $>\mathrm{A}$ and c. $275 \mathrm{G}>\mathrm{A}$ in exon 1 of KRT5], no association has been reported between EBS and these variants so far. Three formerly reported mutations, also detected (two in exon 6 of KRT14: c.1130T $>\mathrm{C}$ (patient 7), c. $1237 \mathrm{G}>\mathrm{A}$ (patient 4 ) and c. $1431 \mathrm{G}>\mathrm{C}$ in exon 7 of KRT5 (patient 5)).

\section{Discussion}

In this study, we identified 9 important variants. Among the identified variants, four of them were not reported previously (Table 3 ).

In family 1 (patients 1 and 2), a mother and her son affected by EBS showed mottled pigmentation phenotype with an autosomal dominant inheritance. Interestingly, 


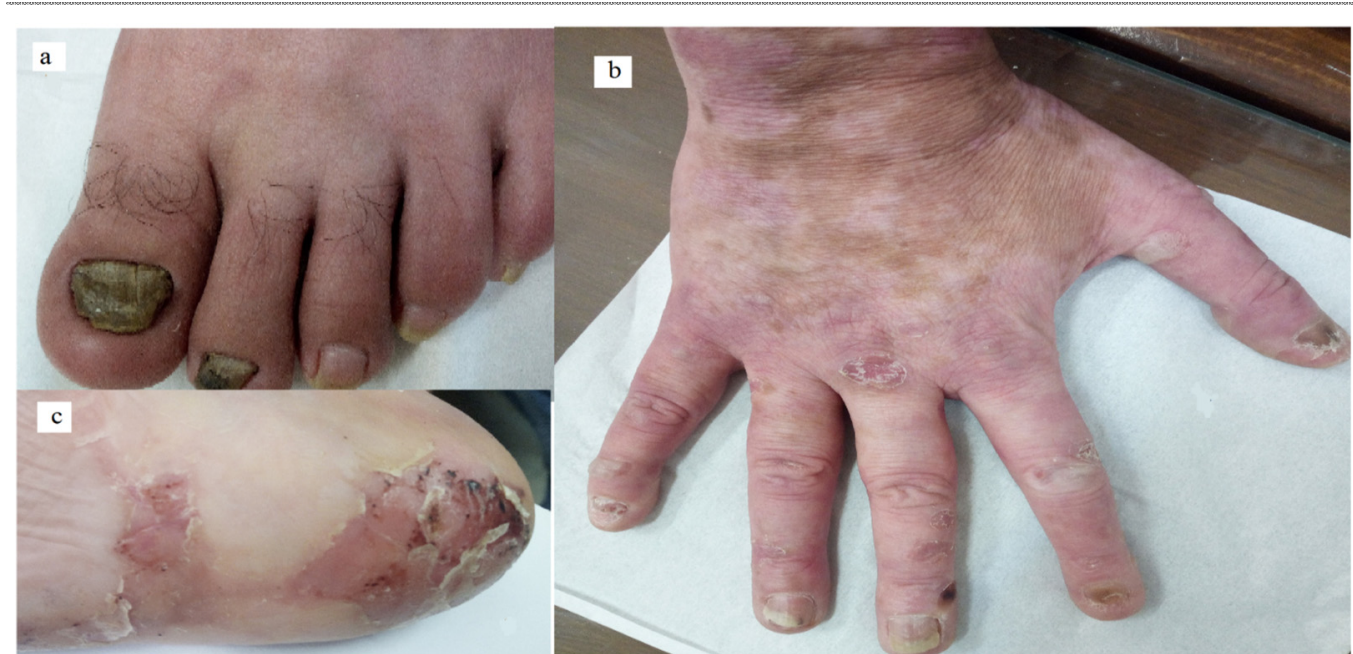

Fig. 1. Some clinical features of patients. a: toe nail dystrophy in patient 1; b: nail dystrophy and then nail losing, Hypopigmentation and hyperpigmentation in patient 5; c: blistering scar in the sole of the foot in patient 4.

Table 3. All variants found in the KRT5 and KRT14 genes in this study

\begin{tabular}{|c|c|c|c|}
\hline Patient & Effect on coding sequence & HGVS coding & HGVS Protein level \\
\hline \multicolumn{4}{|l|}{ KRT5 } \\
\hline 1 and 2 & Missense & c. $287 \mathrm{G}>\mathrm{A}$ & G96D \\
\hline 1,2 and 15 & Missense & c.289T>A (N) & F97I \\
\hline 4 & Missense & c. $275 \mathrm{G}>\mathrm{A}$ & G92E \\
\hline 14 & Missense & c. $1190 \mathrm{G}>\mathrm{T}(\mathrm{N})$ & R397I \\
\hline 14 & Nonsense & c. $1330 \mathrm{C}>\mathrm{T}(\mathrm{N})$ & Q444* \\
\hline 5 & Missense & c. $1249 \mathrm{G}>\mathrm{C}(\mathrm{N})$ & A417P \\
\hline 5 & Missense & c. $1431 \mathrm{G}>\mathrm{C}$ & E477D \\
\hline \multicolumn{4}{|l|}{ KRT14 } \\
\hline 7 & Missense & c. $1130 \mathrm{~T}>\mathrm{C}$ & $\mathrm{I} 377 \mathrm{~T}$ \\
\hline 4 & Missense & c. $1237 \mathrm{G}>\mathrm{A}$ & A413T \\
\hline
\end{tabular}

their clinical features (Table 2) were modified and reduced symptom severity over time. Two heterozygous variants identified in KRT5 gene were located within the head domain of keratin 5 protein (Fig. 2a). Since the mutations in this region appeared to be consistent with mottled pigmentation phenotype, therefore a genotypephenotype correlation was observed (23). The first variant, which is considered as a disease-causing variant, is c. $287 \mathrm{G}>\mathrm{A}$ with G96D (p.Gly96Asp) effect. According to the ACMG guideline, this variant is considered as an Uncertain Significance by getting scores PP3, PP4 (due to patient's phenotype highly specific for the gene) and PM2 (because of this variant absent in South Asian population). The other variant (c.289T $>$ A with F97I (p.Phe97Ile) effect) was a novel genetic variant. According to the ACMG guidelines by getting score PM2, this variant is considered as Uncertain Significance. Patient 15 (in family 12) had very milder symptoms than family 1 and unexpectedly carried de novo c.289T $>$ A variant. This suggests that this variant has a possible synergic genetic effect with c. $287 \mathrm{G}>\mathrm{A}$ variant.

Patient 4 (in family 3) was one of the interesting cases in this study because of having a double heterozygous state for KRT5 and KRT14 genes. His clinical features were concordant with EBS, Koebner type. An important identified variant was c. $1237 \mathrm{G}>\mathrm{A}$ in KRT14 gene. First report of this variant was in a Taiwanese patient with EBS, Koebner type (24). However, in the study conducted by Ken Natsuga et al. (25), in a Japanese family, three normal Japanese had c.1237G $>$ A transition (p.Ala413Thr) within KRT14 and they did not have any history of skin fragility or nail dystrophy. But what is more challenging, is a case report of EBS, Koebner type (generalized intermediate) by Wakiguchi et al. (26), which is a double heterozygote patient; it is described that one of the causative mutations was c. $1237 \mathrm{G}>\mathrm{A}$ (p.Ala413Thr) in KRT14 and another mutation in KRT5. In the mentioned study, mother and sister of the patient were asymptomatic and carried c. $1237 \mathrm{G}>\mathrm{A}$ in the KRT14 gene, but no mutation in KRT5 gene. Another important variant found in patient 4, was c. $275 \mathrm{G}>\mathrm{A}$ in KRT5 gene with G92E (p.Gly92Glu) effect. This variant is located in the head domain of keratin 5 protein (Fig. 2a) and according to the ACMG guideline, considered as Uncertain Significance (because of two scores: PP3 and PM2). However, it is important to note that c. $1237 \mathrm{G}>\mathrm{A}$ in $K R T 14$ is located in the terminal site of the helix2B motif (IF rod) (Fig. 2b) and is concordant with the phenotype of the patient. Therefore the presence of these two variants maybe suggested a digenic pattern of inheritance.

An unequivocal Koebner type phenotype was observed in patient 14(in family 11). Mutation analysis revealed two novel variants in KRT5 gene in a compound heterozygous state and an autosomal recessive inheritance in this patient. Both of these variants are located in the helix $2 \mathrm{~B}$ motif (IF rod domain) of keratin5 protein (Fig. 2a) that is concordant with the patient's phenotype (genotypephenotype correlation). The first variant is a nonsense variant $(\mathrm{c} .1330 \mathrm{C}>\mathrm{T})$ in exon 7 of KRT5 with Q444* (p.Gln444Ter) effect. c. $1330 \mathrm{C}>\mathrm{T}$ in KRT5 by getting 


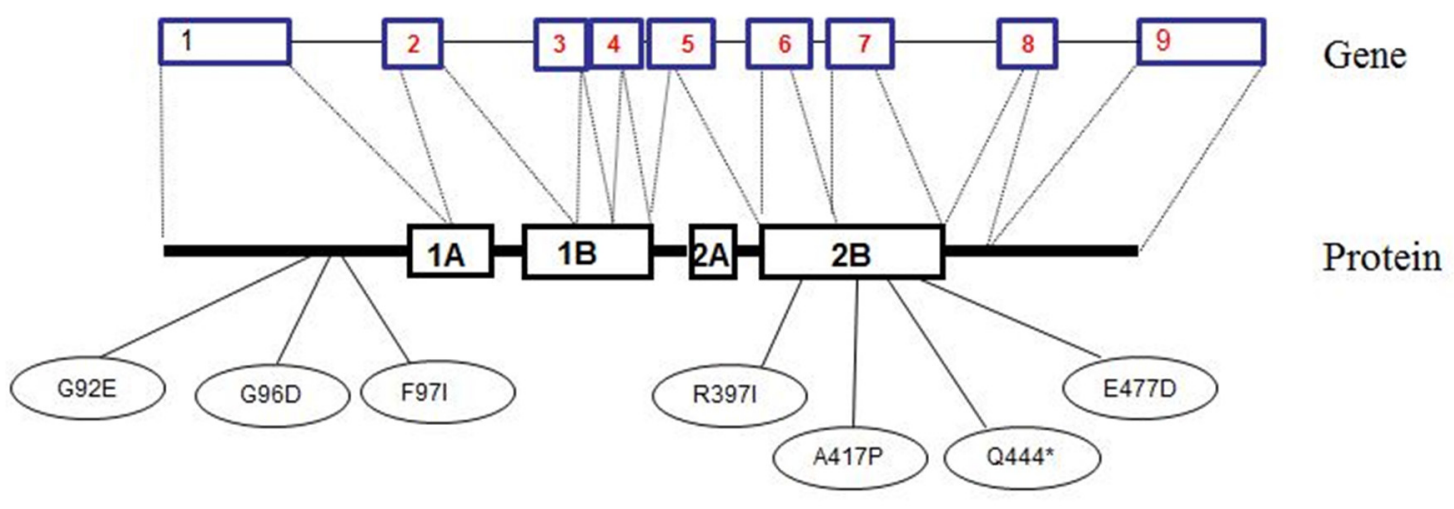

b KRT14 and Keratin 14

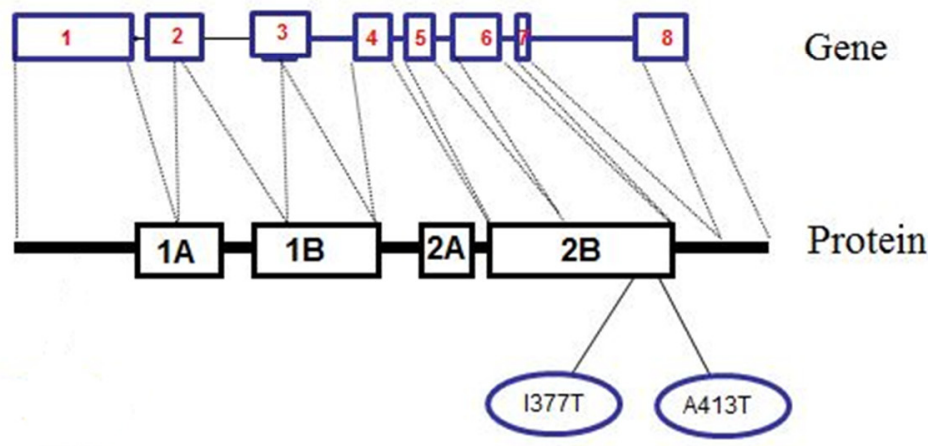

Fig. 2. Schematic picture from variants in KRT5 and KRT14 genes. a: KRT5 exons and protein; b: KRT14 exons and protein

PM1, PM2, PP3 and PVS1 ACMG scores classified as a Pathogenic variant. Another novel variant is c.1190G $>$ T (p.Arg397Ile) in exon 6 of KRT5. ACMG scores for this variant are PM1, PM2, and PP3 that fall into the Uncertain Significance category.

An unclear intermediate phenotype between DowlingMeara and Koebner type was characterized by a probable autosomal recessive inheritance that was observed in patient 5 . This patient was compound heterozygous for both variants c. $1249 \mathrm{G}>\mathrm{C}$ and c. $1431 \mathrm{G}>\mathrm{C}$ in KRT5 gene. Both were located at the helix $2 \mathrm{~B}$ motif (IF rod domain) of keratin 5 protein (Fig. 2a) and they were correlated with Dowling-Meara patient's phenotype. c. $1249 \mathrm{G}>\mathrm{C}$ was a novel variant (being PM1, PM2 and PP3) and considered as an Uncertain Significance. c. $1431 \mathrm{G}>\mathrm{C}$ transition in KRT5 (E477D (p.Glu477Asp)) in a heterozygous state was previously reported in a patient with EB simplex Dowling-Meara accompanied by verrucous carcinoma (27). However, a study by Homberg M et al. (28), suggested that E477D in Keratin 5 for causing severe generalized EBS requires genetic modifiers. The probable genetic modifier for this phenotype in patient 5 can be $1249 \mathrm{G}>\mathrm{C}$ variant.

The c.1130T $>\mathrm{C}$ transition in exon 6 of KRT14 gene (I377T (p.Ile377Thr)) was found in a homozygous state in patient 7(in family 6). This mutation was first previously reported by Rugg EL et al. (29) in a patient with localized EBS (Weber-Cockayne) and subsequently, in 2016, it was described by Vahidnezhad $\mathrm{H}$ et al. (30) in a large Iranian family with a high degree of consanguineous marriage. According to their observations, semi-dominant inheritance was suggested for this genetic alteration and its impacts (30). However, in this study, the patient's clinical features (Table 2) were severe while his mother and father were asymptomatic (only have minor blisters in the sole of the foot after a long walking). Therefore, it was difficult to determine the inheritance pattern. However, it appears that the homozygous state caused Koebner type; and the heterozygous state developed Weber-Cockayne.

In this study, 15 EBS patients were screened for sequence variation in exons 1, 6-7 of KRT5 and exons 1, 4-7 of KRT14. Seven of them were described at the molecular level. Patients with no variation in mentioned exons might have mutations in other exons of KRT5 and KRT14 or other genes with overlapping phenotypes such as PLEC,COL17A1 and ITGB4 $(23,31)$. Moreover, para mutations as epigenetic phenomena may also be involved in the pathogenesis of EBS (32).

\section{Conclusion}

We found 9 important variants in KRT5 and KRT14 genes. According to Our data, for rapid mutation screen- 
ing of EBS, we recommend mutation analysis of the hotspots of these genes. Genotype-phenotype correlation can be useful for the interpretation of molecular variants. Finally, next generation sequencing can be an alternative method for mutation detection and copy number variation analysis in patients with EBS.

\section{Acknowledgments}

This study was supported by a research committee foundation grant no. 96-01-30-30550 of Iran University of Medical Sciences. We wish to thank the patients and their families for participating in this study, and staff at the department of genetics at Iran University of Medical Sciences.

\section{Conflict of Interests}

The authors declare that they have no competing interests.

\section{References}

1. Gu LH, Coulombe PA. Keratin function in skin epithelia: a broadening palette with surprising shades. Curr Opin Cell Biol. 2007;19(1):13-23.

2. Gedde-Dahl T, Anton-Lamprecht I. Epidermolysis bullosa. Emery and Rimoin's principles and practice of medical genetics. 1996;1:1225-78.

3. Horn H, Priestley G, Eady R, Tidman M. The prevalence of epidermolysis bullosa in Scotland. Br J Dermatol. 1997;136(4):560-4.

4. Coulombe PA, Hutton ME, Letal A, Hebert A, Paller AS, Fuchs E. Point mutations in human keratin 14 genes of epidermolysis bullosa simplex patients: genetic and functional analyses. Cell. 1991;66(6):1301-11.

5. Lane E, Rugg E, Navsaria H, Leigh I, Heagerty A, Ishida-Yamamoto A, et al. A mutation in the conserved helix termination peptide of keratin 5 in hereditary skin blistering. Nature. 1992;356(6366):244.

6. Bonifas J, Rothman A, Epstein E. Epidermolysis bullosa simplex: evidence in two families for keratin gene abnormalities. Science. 1991;254(5035):1202-5.

7. Kim S, Coulombe PA. Intermediate filament scaffolds fulfill mechanical, organizational, and signaling functions in the cytoplasm. Genes Dev. 2007;21(13):1581-97.

8. Coulombe PA, Kerns ML, Fuchs E. Epidermolysis bullosa simplex: a paradigm for disorders of tissue fragility. $\mathrm{J}$ Clin Invest. 2009;119(7):1784-93.

9. Herrmann H, Strelkov SV, Burkhard P, Aebi U. Intermediate filaments: primary determinants of cell architecture and plasticity. J Clin Invest. 2009;119(7):1772-83.

10. Arin MJ. The molecular basis of human keratin disorders. Hum Genet. 2009;125(4):355-73.

11. Ciubotaru D, Bergman R, Baty D, Indelman M, Pfendner E, Petronius D, et al. Epidermolysis bullosa simplex in Israel: clinical and genetic features. Arch Dermatol. 2003;139(4):498-505.

12. Szeverenyi I, Cassidy AJ, Chung CW, Lee BT, Common JE, Ogg $\mathrm{SC}$, et al. The Human Intermediate Filament Database: comprehensive information on a gene family involved in many human diseases. Hum Mutat. 2008;29(3):351-60.

13. Yiasemides E, Trisnowati N, Su J, Dang N, Klingberg S, Marr P, et al. Clinical heterogeneity in recessive epidermolysis bullosa due to mutations in the keratin 14 gene, KRT14. Clin Exp Dermatol. 2008;33(6):689-97.

14. Sa'd JA, Indelman M, Pfendner E, Falik-Zaccai TC, Mizrachi-Koren M, Shalev S, et al. Molecular epidemiology of hereditary epidermolysis bullosa in a Middle Eastern population. J Invest Dermatol. 2006;126(4):777-81.

15. Uitto J, Richard G. Progress in epidermolysis bullosa: from eponyms to molecular genetic classification. Clin Dermatol. 2005;23(1):33-40.

16. Uitto J, Richard G, editors. Progress in epidermolysis bullosa: genetic classification and clinical implications. Am $\mathrm{J}$ Med Genet C Semin Med Genet; 2004: Wiley Online Library.

17. Liovic M, Stojan J, Bowden PE, Gibbs D, Vahlquist A, Lane EB, et al. A novel keratin 5 mutation (K5V186L) in a family with EBS-K: a conservative substitution can lead to development of different disease phenotypes. J Invest Dermatol. 2001;116(6):964-9.

18. Sørensen CB, Ladekjær-Mikkelsen AS, Andresen BS, Brandrup F, Veien NK, Buus SK, et al. Identification of novel and known mutations in the genes for keratin 5 and 14 in Danish patients with epidermolysis bullosa simplex: correlation between genotype and phenotype. J Invest Dermatol. 1999;112(2):184-90.

19. Murrell DF, Trisnowati N, Miyakis S, Paller AS. The yin and the yang of keratin amino acid substitutions and epidermolysis bullosa simplex. J Invest Dermatol. 2011;131(9):1787-90.

20. Fine JD, Eady RA, Bauer EA, Bauer JW, Bruckner-Tuderman L, Heagerty A, et al. The classification of inherited epidermolysis bullosa (EB): Report of the Third International Consensus Meeting on Diagnosis and Classification of EB. J Am Acad Dermatol. 2008;58(6):931-50.

21. Nasiri H, Forouzandeh M, Rasaee M, Rahbarizadeh F. Modified salting-out method: high-yield, high-quality genomic DNA extraction from whole blood using laundry detergent. J Clin Lab Anal. 2005;19(6):229-32.

22. García M, Santiago J, Terrón A, Hernández-Martín A, Vicente A, Fortuny C, et al. Two novel recessive mutations in KRT14 identified in a cohort of 21 Spanish families with epidermolysis bullosa simplex. Br J Dermatol. 2011;165(3):683-92.

23. Khani P, Ghazi F, Zekri A, Nasri F, Behrangi E, Aghdam AM, et al. Keratins and epidermolysis bullosa simplex. JCell Physiol. 2018;234(1):289-97.

24. Chao SC, Yang MH, Lee SF. Novel KRT14 mutation in a Taiwanese patient with epidermolysis bullosa simplex (Kobner type). J Formos Med Assoc. 2002 Apr;101(4):287-90.

25. Natsuga K, Nishie W, Smith BJ, Shinkuma S, Smith TA, Parry DA, et al. Consequences of two different amino-acid substitutions at the same codon in KRT14 indicate definitive roles of structural distortion in epidermolysis bullosa simplex pathogenesis. J Invest Dermatol. 2011 Sep;131(9):1869-76.

26. Wakiguchi H, Hasegawa S, Maeba S, Kimura S, Ito S, Tateishi H, et al. A Sporadic Neonatal Case of Epidermolysis Bullosa Simplex Generalized Intermediate with KRT5 and KRT14 Gene Mutations. AJP Rep. 2016 Mar;6(1):e108-11.

27. Schumann H, Roth W, Has C, Volz A, Erfurt-Berge C, Magin TM, et al. Verrucous carcinoma in epidermolysis bullosa simplex is possibly associated with a novel mutation in the keratin 5 gene. Br J Dermatol. 2012 Oct;167(4):929-36.

28. Homberg M, Ramms L, Schwarz N, Dreissen G, Leube RE, Merkel $\mathrm{R}$, et al. Distinct impact of two keratin mutations causing epidermolysis bullosa simplex on keratinocyte adhesion and stiffness. J Invest Dermatol.. 2015;135(10):2437-45.

29. Rugg EL, Horn HM, Smith FJ, Wilson NJ, Hill AJ, Magee GJ, et al. Epidermolysis bullosa simplex in Scotland caused by a spectrum of keratin mutations. J Invest Dermatol.. 2007;127(3):574-80.

30. Vahidnezhad H, Youssefian L, Saeidian AH, Mozafari N, Barzegar M, Sotoudeh S, et al. KRT5 and KRT14 Mutations in Epidermolysis Bullosa Simplex with Phenotypic Heterogeneity, and Evidence of Semidominant Inheritance in a Multiplex Family. J Invest Dermatol. 2016;136(9):1897.

31. Koss-Harnes D, Jahnsen F, Wiche G, Soyland E, Brandtzaeg P, Gedde-Dahl Jr T. Plectin abnormality in epidermolysis bullosa simplex Ogna: non-responsiveness of basal keratinocytes to some anti-rat plectin antibodies. Exp Dermatol. 1997;6(1):41-8.

32. Cuzin F, Grandjean V, Rassoulzadegan M. Inherited variation at the epigenetic level: paramutation from the plant to the mouse. Curr Opin Genet Dev. 2008;18(2):193-6. 